\title{
Fold Change
}

National Cancer Institute

\section{Source}

National Cancer Institute. Fold Change. NCI Thesaurus. Code C60693.

An indication of the magnitude difference between two values specified as the number of multiples of the first value to the second value (e.g., from 10 to 20 is a 2 -fold increase, from 10 to 50 is a five-fold increase). 